\title{
Abandono no andebol na Região Autónoma da Madeira
}

\author{
Norberta Fernandes ${ }^{1}$ \\ Abel Correia ${ }^{2}$ \\ Ana Maria Abreu 1
}

\author{
${ }^{1}$ Universidade da Madeira \\ Portugal \\ ${ }^{2}$ Faculdade de Motricidade Humana \\ Universidade Técnica de Lisboa \\ Portugal
}

\section{RESUMO}

Esta investigação pretendeu estudar o abandono desportivo no andebol na ilha da Madeira. Os atletas inscritos pela primeira vez na Federação, no período entre 1995 e 2004, constituíram a amostra, com dimensão 4721. Desta, extraímos uma sub-amostra, formada pelas raparigas que iniciaram a modalidade entre os 10 e os 14 anos e pelos rapazes que iniciaram entre os 10 e os 15, num total de 2293 atletas. Foram aplicados questionários a atletas no activo e àqueles que tinham abandonado, perfazendo 230 atletas. No domínio metodológico, foram calculadas taxas de abandono para a amostra e sub-amostra tendo em conta a idade de entrada, o género, o número de épocas e a idade de abandono. $\mathrm{Na}$ análise dos questionários, efectuou-se o teste de Pearson para detectar diferenças entre os dois grupos. Os resultados do estudo indicaram que a taxa de abandono sobe à medida que aumenta a idade de entrada dos atletas. A percentagem de abandono nas primeiras épocas é tanto maior quanto maior for a idade de entrada dos mesmos. A principal conclusão resultante dos questionários apontou no sentido de os atletas que estavam no activo serem mais comprometidos com o andebol do que aqueles que já tinham abandonado.

Palavras-chave: abandono, andebol, compromisso.

\section{ABSTRACT \\ Drop-out of handball in the Madeira Autonomous Region}

This investigation has the purpose of study the dropout in the handball in Madeira Island. A sample of 4721 athletes was collected from the federation, between 1995 and 2004. We worked with a sub-sample, with girls that started practice handball between the ages of 10 and 14 years old and with boys that started between 10 and 15, in a total of 2293 athletes. The questionnaires were applied to athletes in the active and to those who dropped out, in a total of 230. In the methodological domain we calculated the average rates of dropout for the sample and sub-sample considering the starting age, the gender, the number of seasons and the age of dropout. Analysing the questionairy, we used the test of "Pearson" to detect the differences between the two groups. The results of the study showed that the median rate of dropout by season increases along side with the starting age of the athletes. Similarly the dropout percentages during the first season are bigger if the starting age is higher. The main results of the questionnaires analysis show that the athletes that were active were more involved with handball than the athletes who have dropped out.

Key-words: dropout, handball, commitment. 


\section{INTRODUÇÃO}

Este estudo visa compreender o fenómeno do abandono desportivo no andebol na Região Autónoma da Madeira, usando os postulados da teoria do intercâmbio social.

A teoria do intercâmbio social(13) começa com a concepção de que o comportamento humano é governado primeiramente pelo desejo de maximizar as experiências positivas e minimizar as experiências negativas. Nesta perspectiva, as pessoas participam em relações e actividades somente enquanto os resultados de participação são suficientemente favoráveis. O favoritismo é determinado pelo balanço entre os benefícios e os custos. Na maioria dos modelos, a análise dos custos/benefícios é expressa por uma variável atractiva, como satisfação( $(8,9)$ ou divertimento(11).

De acordo com Thibaut e Kelley(13), a decisão de manter-se numa relação ou numa actividade não é baseada somente no balanço entre os benefícios e os custos. A decisão de persistir ou abandonar também depende da visibilidade e da atracção pelas alternativas.

Consequentemente, alguém pode escolher continuar envolvido no desporto, mesmo que os custos excedam os benefícios (recompensas) porque não existem alternativas ou não são acessíveis. No domínio desportivo, recompensas poderão envolver consequências tangíveis, como as medalhas, diplomas e outros troféus, ou até algumas vezes dinheiro. Mas também são psicológicas, como atingir os objectivos desejados. O paradigma do intercâmbio social foi considerado efectivo na predição do compromisso e permite distinguir entre indivíduos que ficam numa relação ou no trabalho e aqueles que abandonam.

Scanlan et al.(11) apresentaram um modelo teórico específico para o desporto - o modelo de compromisso desportivo - que está centrado em processos psicológicos subjacentes à participação desportiva. Este modelo tem a sua base na psicologia organizacional e social.

O compromisso é o termo que significa a força motivacional por trás da persistência. No domínio desportivo, Scanlan et al.(11) definem o compromisso como um constructo psicológico, que representa o desejo para continuar na participação desportiva. Em resumo, o compromisso representa o estado psicológico individual de ligação à sua participação ou uma força motivacional para continuar envolvido.
O compromisso desportivo pode ser estabelecido em função de quatro antecedentes: a análise dos custos/benefícios, feita pelo atleta, da sua experiência desportiva; uma atracção ou não pelas alternativas desportivas; nível de investimento; os sentimentos do atleta acerca dos constrangimentos sociais. No domínio desportivo, os investimentos são o tempo, o esforço e o dinheiro que os indivíduos colocam directamente no seu envolvimento e que não pode ser recuperado se desistirem(11). Existe a hipótese de que um grande investimento pessoal irá promover um grande compromisso desportivo. O constrangimento social acentua a pressão social para participar, é necessário manter-se na actividade para agradar os outros $(1,5,11,12)$. Fazendo o transfere para o desporto significa que outros incluem pais, amigos, treinadores e outras pessoas no geral(11). Apesar das inúmeras razões apontadas pelos jovens conducentes à sua participação desportiva,

Petlichkoff(6) identificou o divertimento como o principal motivo pelo qual estes se mantêm envolvidos nas actividades ou a abandonam.

Contudo, embora crianças e adolescentes possam argumentar que a razão da participação em actividades desportivas é o divertimento, este pode não ter o mesmo significado para ambos. Para uma criança pode ter um significado relacionado com os aspectos do envolvimento desportivo e do próprio jogo, enquanto que para um adolescente pode ser conectado com a excitação competitiva(2).

Uma revisão de literatura sobre a motivação em jovens atletas definiram como fontes de divertimento 6 dimensões, nomeadamente, competência, autonomia, relação com os outros, progresso, apoio do treinador e jogar muito tempo. Estas dimensões foram consideradas preditoras da satisfação dada pelo andebol. Como tal, também foram utilizadas neste estudo para definir divertimento no modelo do compromisso desportivo.

Burton ${ }^{(3)}$ menciona que as percentagens de abandono desportivo poderão eventualmente ser interpretadas de um modo optimista ou pessimista. Na primeira perspectiva, refere que o abandono desportivo faz necessariamente parte da natureza dos jovens e adolescentes que, pelo método experimental da tentativa e erro, procuram encontrar a actividade que mais lhes agrada e lhes permita atingir a natural 
Masculinos

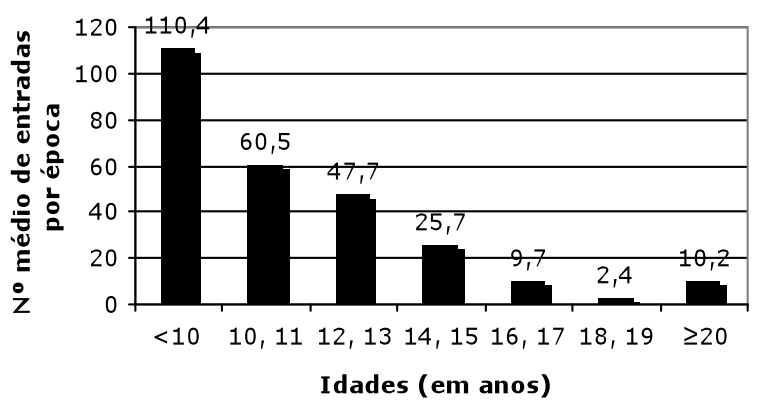

Femininos

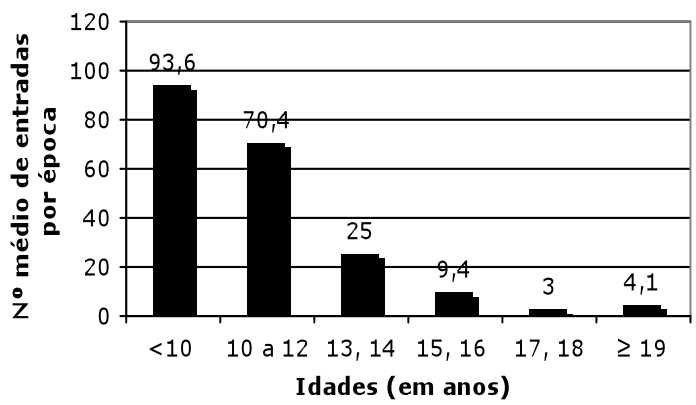

Figura 1. Número médio de entradas por época.

necessidade de afirmação das suas capacidades.

Numa perspectiva pessimista, o mesmo autor indica que essas percentagens de abandono podem pôr em evidência que os programas e as exigências das diferentes modalidades desportivas não estão de acordo com o nível de capacidades e maturação dos jovens que as praticam. Esta situação impede que eles atinjam os objectivos que perspectivaram obter quando se envolveram na prática desportiva.

Petlichkoff(7) refere que todos os anos cerca de 70 milhões de jovens atletas em todo o planeta, com idades compreendidas entre os 6 e os 16 anos, aderem a práticas desportivas. Paradoxalmente, também estimou que até cerca dos 17 anos, $80 \%$ dos jovens abandonaram o desporto organizado em que estavam envolvidos.

Masculinos

Existem vários tipos de abandono referidos na literatura. Assim é importante definir o conceito de abandono desportivo que utilizámos para este estudo. Consideramos abandono desportivo no andebol, como sendo o abandono da prática federada do andebol.

\section{MATERIAL E MÉTODOS \\ Amostra}

A amostra foi recolhida tendo por base os atletas inscritos pela primeira vez na Federação Portuguesa de Andebol nas épocas 1995/96 a 2004/05 (10 épocas), o que totalizou 4721 indivíduos. O número médio de entradas por época, por género e por idade pode ser observado nos gráficos da Figura 1.

Para tratar especificamente as questões do abandono, delimitámos a nossa amostra em termos de idade, com base no número médio de entradas por época (Figura 2). Assim, trabalhámos com as raparigas que iniciaram a modalidade entre os 10 e os 14 anos e com os rapazes que iniciaram entre os 10 e os 15 . 
Os atletas com menos de 10 anos foram excluídos da análise pois nesta etapa de formação os objectivos passam por sensibilizar os atletas para a modalidade. Apesar de esses atletas representarem a maior percentagem da amostra em todas as épocas, como em média cerca de $45 \%$ abandonaram após a primeira época, admitimos que muitos deles estão em fase de experimentação e, por tentativa e erro, irão optar por esta modalidade ou por outra.

Com a ressalva do ponto anterior, os atletas que analisámos foram aqueles cujas idades apresentaram as maiores percentagens de entradas. De facto, a percentagem de entradas decresce bruscamente para além dos escalões considerados em cada género. Para a aplicação dos questionários, a nossa amostra foi constituída por 230 atletas (180 atletas no activo, 50 atletas que abandonaram).

\section{Questionário}

Com base nas percepções que definimos para o divertimento e nas dimensões de alternativas do envolvimento e constrangimentos sociais aplicámos o questionário para obter informações relativas a três situações: caracterização do atleta (data de nascimento, género, número de anos de prática e de horas de treino, nível competitivo e grau de empenhamento); razões que levaram ao abandono e, paralelamente, razões pelas quais os atletas se mantêm na prática. Para cada dimensão e respectivas componentes foram criadas frases, sendo a escala de Likert, de 1 (corresponde a discordo totalmente) a 5 (corresponde a concordo totalmente) a utilizada com mais frequência. Para avaliar a consistência dos questionários calculámos o coeficiente de "alpha" de Cronbach e obtivemos os seguintes valores: para o questionário aplicado aos atletas activos o valor foi "alpha" $=0.692 \mathrm{e}$ mediu 48 itens. Para o questionário aplicado aos atletas que abandonaram o valor foi "alpha" $=0.784$ e mediu 53 itens.

Os questionários foram aplicados aos atletas que tinham abandonado a prática desportiva federada, de ambos os sexos e com as idades onde esse processo acontece com maior frequência. Fomos à procura daqueles que abandonaram apenas na última época do nosso estudo (2004/2005), para que não houvesse um distanciamento muito grande do acontecimento estudado.
Os atletas que estavam no sistema e que tinham as idades determinadas pelo estudo, foram igualmente interrogados. Assim ficámos com uma perspectiva integrada do andebol federado da Região Autónoma da Madeira.

A aplicação dos questionários foi realizada na época 2006/2007. A amostragem dos atletas que abandonaram foi por conveniência porque muitos dos atletas encontrados não quiseram participar no estudo e outros não se encontravam na ilha.

Os questionários que aplicámos aos atletas que abandonaram e àqueles que ainda se mantinham no sistema desportivo foram muito semelhantes. A diferença prendeu-se com questões relacionadas com os tempos verbais.

Depois de seleccionar os atletas que já tinham abandonado, optámos por procurá-los nas escolas da sua área de residência e aplicar-lhes directamente os questionários. O envio do questionário para casa pareceu-nos pouco eficaz, visto que muitos dos atletas foram contactados primeiro por telefone e demonstraram pouca receptividade para o assunto. Outra questão que constatámos foi o facto de muitos atletas já terem regressado à prática da modalidade em questão e outros não estarem na região, por vários motivos.

\section{Tratamento dos dados}

Para caracterização da amostra calculámos médias, por género e por faixa etária. Relativamente à subamostra, para além do procedimento anterior, apresentámos mais medidas de localização (mínimo, primeiro quartil, mediana, terceiro quartil e máximo) referentes ao número de épocas, à idade de abandono, por género e por faixa etária. Além disso, utilizámos a análise de sobrevivência para determinar as estimativas de Kaplan-Meier da função de sobrevivência, por género, quer relativo ao número de épocas, quer à idade de abandono.

Os procedimentos estatísticos utilizados nos questionários foram: teste de Pearson do qui-quadrado; gráficos de barras para caracterização das respostas de algumas questões.

\section{RESULTADOS}

Com base na amostra inicial, a taxa média de abandono, por época, nas raparigas é de $37 \%$, enquanto que 

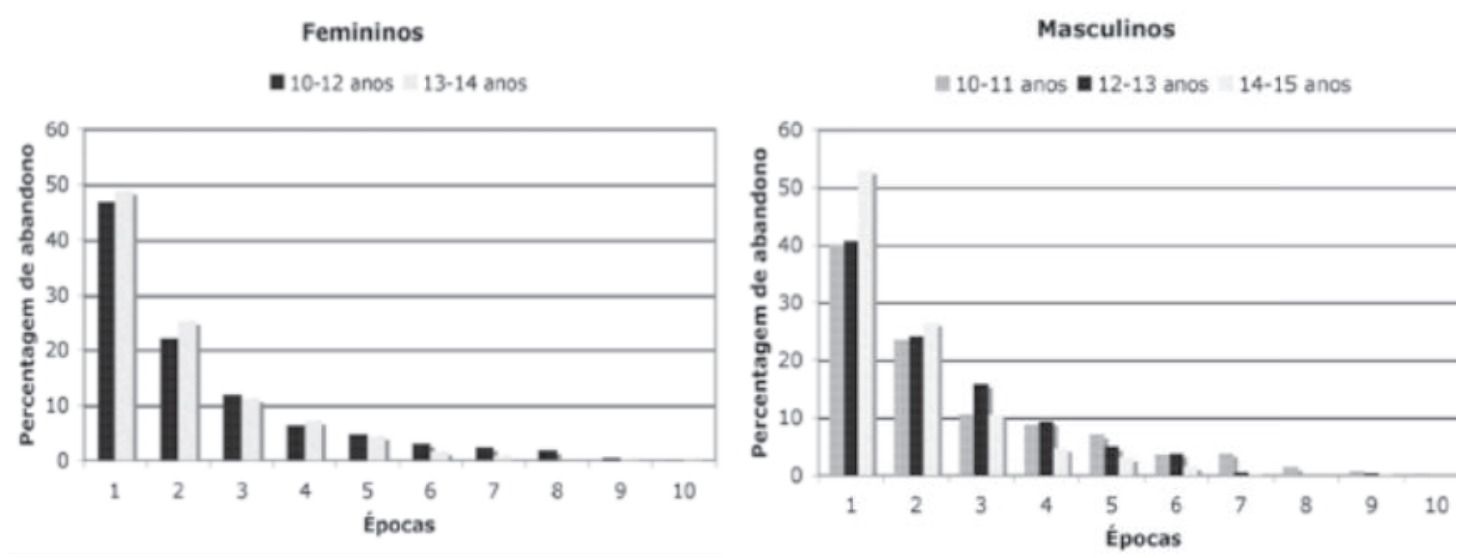

Figura 3. Percentagens de abandono, por época, faixas etárias e género.
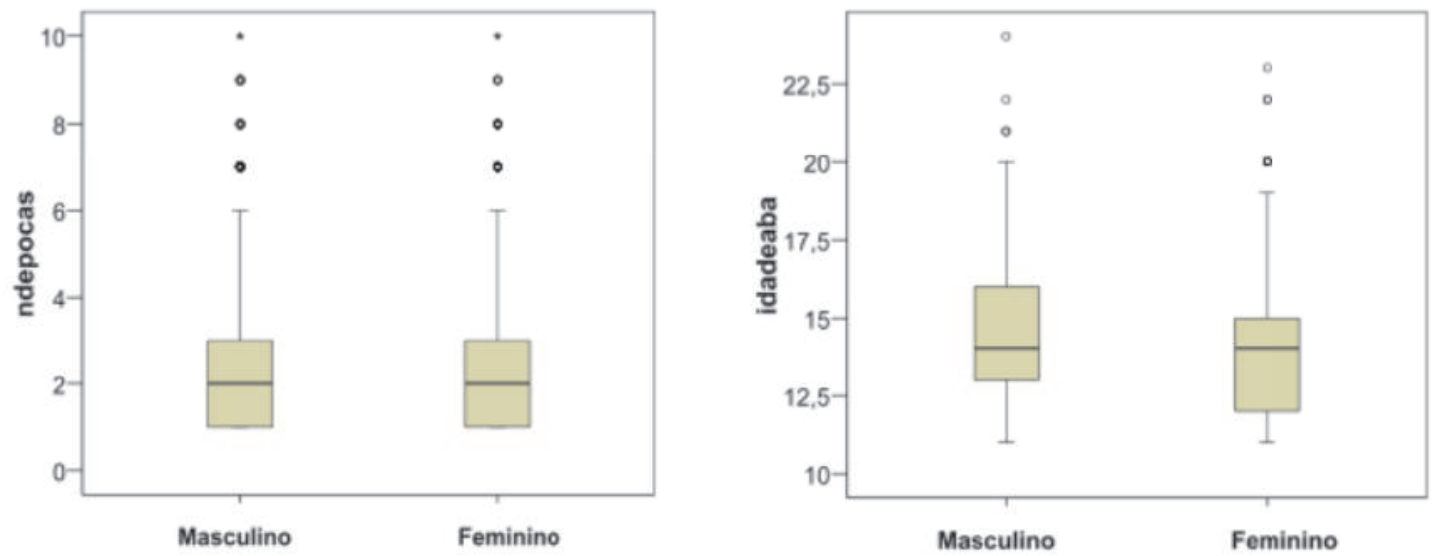

Figura 4. Distribuições do número de épocas e da idade de abandono nos dois géneros.

nos rapazes é de $33 \%$. No entanto, em ambos os géneros, as taxas têm valores díspares ao longo das épocas, embora sem apresentar qualquer tipo de tendência. Relativamente à sub-amostra, no caso do género feminino, verificámos que a taxa média de abandono é de $38 \%$ para as atletas que iniciaram a modalidade entre os 10 e os 12 anos e de $44 \%$ entre os 13 e os 14 . Quanto ao género masculino, a taxa é de $27 \%$ entre os 10 e os 11 anos, de $37 \%$ entre os 12 e os 13 e de $50 \%$ entre os atletas que iniciam com 14 ou 15 anos. Uma vez que existe uma correlação negativa significativa entre a idade em que o atleta se iniciou na modalidade e o número de épocas que se manteve em actividade, ou seja, quanto menor é a idade de entrada maior é o número de épocas, averiguámos a percentagem de abandono de acordo com o número de épocas, tendo em conta a idade de início.

Ao observar os gráficos da Figura podemos notar que a percentagem de abandono é muito elevada nas duas primeiras épocas, tanto no género masculino como no feminino. Nas raparigas a percentagem é semelhante para as duas faixas etárias ao longo das épocas embora a faixa etária dos 13 e 14 anos apresente um ligeiro acréscimo nas duas primeiras épocas, compen- 
sado por um decréscimo notório a partir da sexta época. Nos rapazes, à excepção da terceira e da sétima época, a percentagem de abandono é semelhante para as faixas etárias 10 e 11 anos e 12 e 13 anos. Relativamente aos 14 e 15 anos, a percentagem é muito elevada nas primeiras épocas, observando-se $90 \%$ de abandono ao fim de apenas três épocas.

Ao analisar a sub-amostra globalmente comparámos as distribuições da idade de abandono e do número de épocas nos dois géneros.

A semelhança dos dois géneros relativa ao número de épocas é bem visível, pois os valores do mínimo (1), primeiro quartil (1), mediana (2), terceiro quartil (3) e máximo (10) coincidem. No entanto, sob o ponto de vista da idade de abandono, as semelhanças resumem-se ao mínimo (11) e à mediana (14). Quanto às diferenças, 25\% das raparigas abandonam até aos 12 anos, enquanto que os rapazes só o fazem até aos 13 . Observa-se o mesmo tipo de diferença relativamente aos $75 \%$, com as raparigas a abandonarem até aos 15 anos e os rapazes até aos 16. Assim, no geral, podemos concluir que as raparigas abandonam a modalidade mais cedo do que os rapazes.

No que diz respeito à aplicação da análise de sobrevivência, começámos por determinar as estimativas de Kaplan-Meier da função de sobrevivência, por género, onde o tempo de vida é o tempo desde que o atleta inicia a modalidade a nível federado até ao

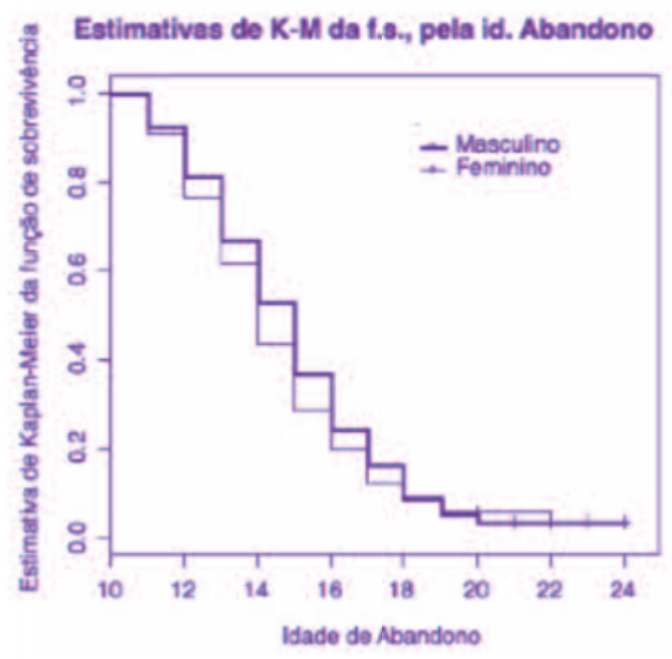

abandono. Os resultados encontram-se na Figura, sendo que, no primeiro caso tivemos em conta o número de épocas, enquanto que no segundo foi a idade de abandono.

Ao analisar o comportamento dos atletas através do número de épocas, novamente é visível a ausência de diferença significativa entre os dois géneros. No entanto, ao analisarmos através da idade de abandono, já podemos notar que, até aos 18 anos, as raparigas têm uma taxa de abandono mais elevada. Além disso, também se observa uma quebra acentuada da prática desportiva dos 13 para os 14 anos nas raparigas e dos 14 para os 15 nos rapazes.

Parece-nos importante realçar algumas diferenças encontradas na análise dos questionários, nomeadamente no género e entre os atletas activos e os que abandonaram. Essas diferenças foram detectadas através do teste de Pearson do qui-quadrado. Apenas apresentámos e discutimos os dados cujos valores de $p$ foram significativos, com a seguinte interpretação: entre 0,05 e 0,01 existem diferenças significativas $\left.{ }^{*}\right)$; entre 0,01 e 0,001 existem diferenças muito significativas $\left({ }^{* *}\right)$; menor do que 0,001 existem diferenças extremamente significativas $\left({ }^{* *}\right)$.

Foi na dimensão compromisso que encontrámos as diferenças mais significativas entre os atletas activos e os que abandonaram, como se pode verificar através da análise das afirmações que se seguem.

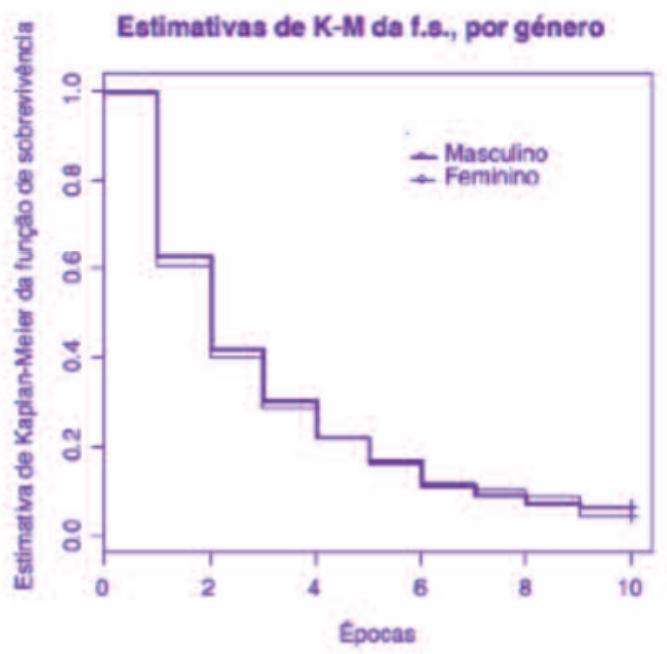

Figura 5. Estimativas de Kaplan-Meier da função de sobrevivência, por género. 
C0.2. Eu estou determinado em continuar a jogar andebol.

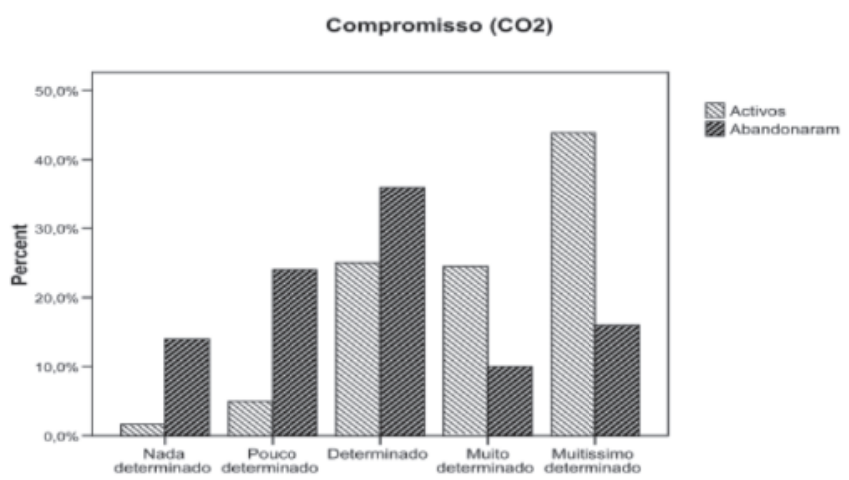

Figura 6. Percentagens das respostas dos atletas activos e daqueles que já abandonaram, pelas diferentes categorias, na questão CO2.

\section{Compromisso (CO3)}

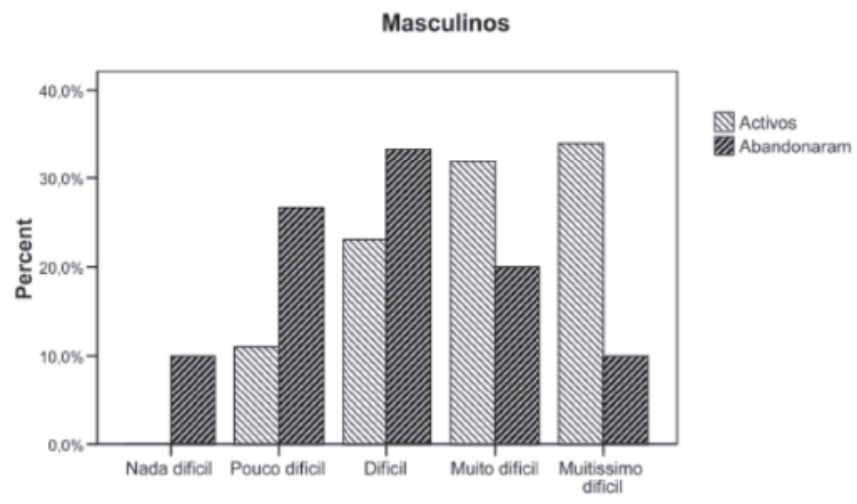

Figura 7. Percentagens das respostas dos atletas activos e daqueles que já abandonaram, pelas diferentes categorias, na questão $\mathrm{CO} 3$.

Compromisso (CO3)

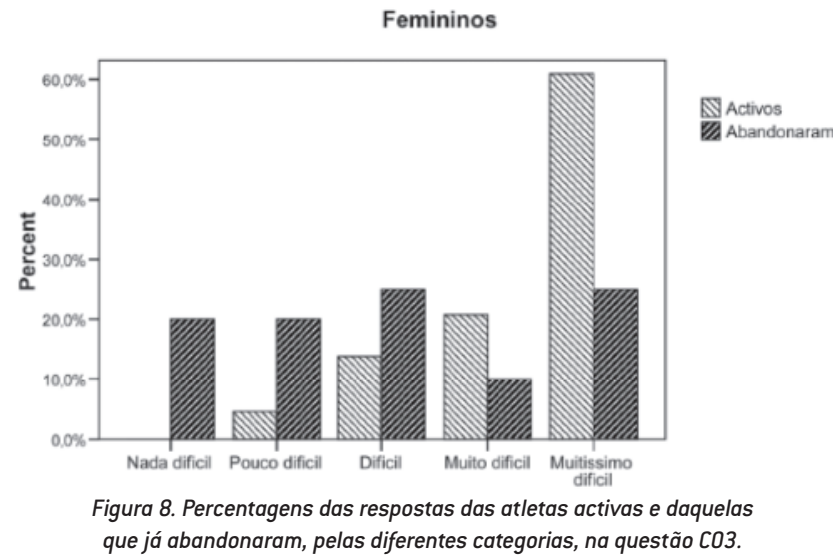

Existem diferenças extremamente significativas entre os atletas activos e os que abandonaram, $\mathrm{p}<.0001$. Nesta questão, os atletas activos apresentam percentagens claramente superiores nas categorias muito determinado e muitíssimo determinado. Os atletas que abandonaram apresentam uma percentagem muito superior nas categorias nada determinado e pouco determinado.

\section{C0.3. É difícil para ti abandonar $\mathrm{o}$ andebol?}

Nesta questão existem diferenças muito significativas entre os rapazes que abandonaram e aqueles que permanecem no activo, $\mathrm{p}=0.001$. Isso pode-se verificar com a ajuda do gráfico que se segue.

As diferenças são mais expressivas nas categorias de muitíssimo difícil, onde os activos apresentam uma percentagem de $35 \%$ e os que abandonaram apenas $9 \%$ aproximadamente. Nas categorias nada difícil e pouco difícil, os atletas que abandonaram apresentam percentagens muito superiores às dos activos, com a particularidade de nenhum destes últimos ter assinalado a primeira categoria.

Existem diferenças extremamente significativas entre as raparigas que estão no activo e aquelas que abandonaram, $\mathrm{p}<0.0001$, como é visível na Figura 8.

As grandes diferenças encontram-se nas categorias dos extremos, ou seja, as activas optaram maioritariamente pela categoria muitíssimo difícil e apresentam uma percentagem nula na categoria nada difícil. As atletas que abandonaram distribuíram-se por todas as categorias de uma forma mais ou menos homogénea.

\section{C0.4. 0 que és capaz de fazer para não abando- nares 0 andebol?}

Os rapazes que estão no activo apresentam diferenças muito significativas em relação aos que abandonaram, $\mathrm{p}=0.001$.

Essas diferenças são bem evidentes nas categorias poucas coisas e muitas coisas (Figura 9).

Na primeira são os atletas que já abandonaram que têm uma percentagem de $38 \%$ versus $9 \%$ e na segunda os activos $35 \%$ versus $3 \%$. 
Compromisso (CO4)

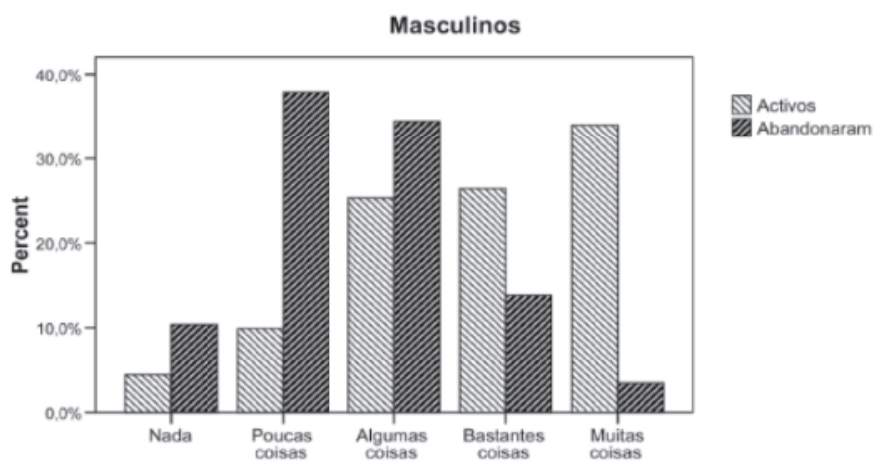

Figura 9. Percentagens das respostas dos atletas activos e daqueles que já abandonaram, pelas diferentes categorias, na questão CO4.

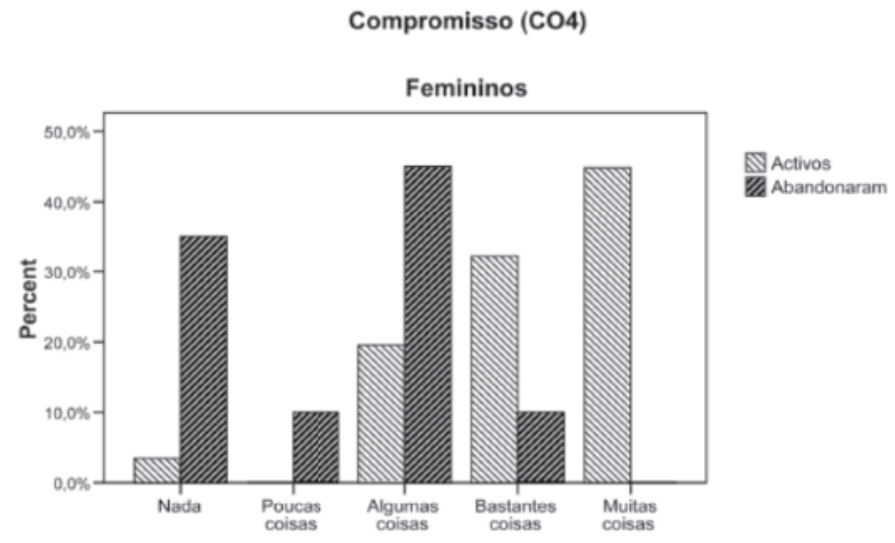

Figura 10. Percentagens das respostas das atletas activas e daquelas que já abandonaram, pelas diferentes categorias, na questão CO4. competência); os atletas inquiridos apresentam uma boa relação com os outros (percepção de relação com os outros); podemos acrescentar que as raparigas se apresentam mais satisfeitas com o papel do treinador (percepção de progresso); os atletas inquiridos, de uma maneira geral, conseguem conciliar os estudos com o andebol (alternativas do envolvimento); em termos gerais a atracção por outras actividades não é uma realidade nesta amostra; os atletas inquiridos não têm preocupações em agradar aos pais nem aos treinadores, apesar da tendência para agradar ao treinador ser ligeiramente superior.

\section{DISCUSSÃO}

Um dos postulados da teoria do intercâmbio social é que as pessoas participam numa actividade, se o balanço entre os custos e os benefícios forem favoráveis ${ }^{(13)}$. É recomendado que os treinadores tenham conhecimento desta realidade quando trabalham com os atletas. Em resumo, e como implicação prática, este estudo sugere que uma das prioridades dos treinadores e de outros líderes desportivos seja a criação de um envolvimento social que permita que os atletas alcancem os seus motivos de participação.

Especificamente, temos de assegurar que as expectativas dos atletas relacionados com o progresso, relação com os outros, competência, autonomia, e suporte dado

Nesta mesma questão existem diferenças extremamente significativas entre as atletas que estão no activo e aquelas que abandonaram, $\mathrm{p}<.000$. As primeiras optaram claramente pelas categorias bastantes coisas e muitas coisas, enquanto que as raparigas que já abandonaram têm uma maior percentagem nas categorias nada e algumas coisas (Figura 10). Nas restantes dimensões e componentes os resultados foram os seguintes: tanto os atletas que estão no activo, como aqueles que abandonaram têm a percepção de que não estagnaram tecnicamente e melhoraram tacticamente no andebol (percepção de pelo treinador sejam alcançados, se quisermos que o divertimento e o correspondente compromisso sejam elevados e que os atletas continuem envolvidos. Da análise dos questionários concluímos que as grandes diferenças entre os praticantes que abandonaram e aqueles que se mantiveram no activo, são as respostas às questões da dimensão compromisso. Os atletas que estavam no activo eram mais comprometidos com o andebol e por isso não abandonaram. O nosso estudo está em consonância com a teoria do intercâmbio social e com o modelo do compromisso desportivo. 
Nas questões da percepção de progresso, tanto os activos como os que abandonaram apresentam-se satisfeitos com o trabalho do treinador em relação ao progresso dos atletas. Poderá ser útil educar os treinadores para o impacto dos seus comportamentos nas motivações dos atletas ${ }^{(14)}$. Um elemento chave poderá ser encorajar os treinadores a utilizar um clima direccionado para a tarefa, no sentido de ajudar os atletas a centrarem-se em dimensões de mestria de actividade e não em dimensões extrínsecas. Assim o sucesso deverá ser definido como o melhoramento pessoal ao contrário de enfatizar a vitória. Nas alternativas do envolvimento, grande parte dos inquiridos não se sentiu atraído por outras actividades, existiu apenas uma pequena percentagem de atletas que abandonaram que optaria por fazer outras coisas. Este facto contraria a linha de investigação que diz que os conflitos de interesse e/ou interesses por outras actividades são os motivos mais consistentes para o abandono desportivo(4). Nos constrangimentos sociais, os atletas inquiridos não têm preocupações em agradar aos pais ou/e aos treinadores, apesar da tendência para agradar ao treinador ser ligeiramente superior. Não existiram sentimentos de obrigatoriedade nesta amostra (activos/abandonaram). Os atletas que abandonaram não sentiram pressão, logo o compromisso diminuiu. Nos investimentos pessoais e especificamente no grau de empenhamento, são os rapazes que abandonaram que tiveram maiores percentagens na categoria quase sempre. Este dado poderá ser revelador de que os jovens abandonaram porque sentiam-se injustiçados ou porque sentiam que mesmo com um grau de empenhamento elevado não conseguiam atingir determinados patamares.

A compreensão do fenómeno do abandono passa necessariamente por um cruzamento de teorias e comparação de paradigmas afins de decidir qual é que melhor poderá explicar este assunto(10). Por vezes, só essas pontes entre as teorias conseguem obter a diversidade dos factores e processos implicados neste fenómeno.

De acordo com os resultados quer da análise descritiva quer da análise de sobrevivência, tendo em conta o número de épocas, pudemos concluir que o género não constituiu uma variável explicativa do fenómeno que estudámos. No entanto, com base na idade de abandono, já notámos alguma diferença. Esta última observação não entra em contradição com a anterior: no primeiro caso estávamos a considerar quantas épocas o atleta se mantinha na modalidade, enquanto que no segundo considerámos qual a idade em que abandonava. Significa pois que as raparigas tendem a iniciar mais cedo o andebol, mas também tendem a abandoná-lo mais cedo.

Concluímos ainda que a taxa média de abandono, por época, sobe à medida que aumenta a idade de entrada dos atletas.

Verificámos também que a percentagem de abandono nas primeiras épocas é tanto maior quanto maior for a idade de entrada dos atletas.

\section{CORRESPONDÊNCIA}

Norberta Fernandes

Edifício Solar da Azenha, Bl. A, $3^{\circ} \mathrm{L}$

9125-018 Caniço

Madeira

E-mail: norfernandes@hotmail.com 


\section{REFERÊNCIAS}

1. Becker S (1960). Notes on concept of commitment. American Sociological Review 66: 32-40

2. Brustad R (1993). Youth in sport: Psychological considerations. In: Handbook of research on sport psychological, 695-717

3. Burton D (1988). The dropout dilemma in youth sport: Documenting the problem and identifying solutions. Youth Athletes 244-266

4. Gould D (1987). Understanding attrition in children's sport. Advances in pediatric sport sciences, $61-85$

5. Kelley H (1983). Love and commitment. Close relationships 265-314

6. Petlichkoff L (1992). Young sport participation and withdrawal: Is it simply a matter of fun? Pediatric Exercise Science 4: $105-110$

7. Petlichkoff L (1993). Group differences on perceived ability, achievement goal orientations, and level of satisfaction during the season. Pedriatric Exercise Science 5: 12-24

8. Rusbult C (1980). Commitment and satisfaction in romantic associations: A test of the investment model. Journal of
Experimental Social Psychology 16: 172-186

9. Rusbult C (1983). A longitudinal test of the investment model: the development of satisfaction and commitment in heterosexual involvement. Journal of Personality and Social Psychology 45: 101-117

10. Sarrazin P, Guillet E (2001). Ils ne se réinscrivent pás! Variables et processus de L`abandone sportive. Théories de la motivation et pratiques sportives 223-254.

11. Scanlan T, Carpenter P, Schmidt G, Simons J, Keeler B (1993). An introduction to the sport commitment model. Journal of Sport \& Exercise Psychology 15: 1-15

12. Sprecher S (1988). Investment model, equity and social support determinants of relationship commitment. Social Psychology Quarterly 51: 318-328

13. Thibaut J, Kelley H (1959). The social psychology of groups. New York: Wiley.

14. Vallerand R, Losier G (1999). An integrative analysis of intrinsic and extrinsic motivation in sport. Journal of Applied Sport Psychology 11: 142-169 